\title{
Environmental influences on the epigenomes of herpetofauna and fish
}

\begin{tabular}{|r|l|}
\hline Journal: & Biochemistry and Cell Biology \\
\hline Manuscript ID & bcb-2015-0111.R1 \\
\hline Manuscript Type: & Mini Review \\
\hline Date Submitted by the Author: & 07-Sep-2015 \\
\hline Complete List of Authors: & $\begin{array}{l}\text { Hammond, S. Austin; University of Victoria } \\
\text { Nelson, Christopher; University of Victoria, } \\
\text { Helbing, Caren; University of Victoria }\end{array}$ \\
\hline Keyword: & fish, epigenetics, amphibia, reptile, histone modifications \\
\hline
\end{tabular}


Environmental influences on the epigenomes of herpetofauna and fish

S. Austin Hammond, Christopher J. Nelson, and Caren C. Helbing

Department of Biochemistry and Microbiology, University of Victoria, P.O. Box 1700, STN CSC, Victoria, British Columbia, V8W 2Y2, Canada

Corresponding Author: Caren C. Helbing, Phone (250) 721-6146, Fax (250) 721-8855, E-mail: chelbing@uvic.ca 


\section{Abstract}

Herpetofauna (amphibians and reptiles) and fish represent important sentinel and indicator species for environmental and ecosystem health. It is widely accepted that the epigenome plays an important role in gene expression regulation. Environmental stimuli, including temperature and pollutants, influence gene activity and growing evidence demonstrates that an important mechanism is through modulation of the epigenome. This has been primarily studied in human and mammalian models; relatively little is known about the impact of environmental conditions or pollutants on herpetofauna or fish epigenomes and the regulatory consequences of these changes on gene expression. Herein, we review recent studies that have begun to address this deficiency, which have mainly focused on limited specific epigenetic marks and individual genes or large-scale global changes in DNA methylation due to the comparative ease of measurement. Greater understanding of the epigenetic influences of these environmental factors will depend on increased availability of relevant speciesspecific genomic sequence information to facilitate chromatin immunoprecipitation and DNA methylation experiments.

Keywords: fish; epigenetics; amphibia; reptile; histone modifications 


\section{Introduction}

Herpetofauna (amphibians and reptiles) and fish frequently contend with variations in temperature, salinity, and aridity, as well as exposure to myriad chemicals and contaminants, over changing seasons and environs. Adaptation to environmental conditions may only be temporary, as in acclimation to low winter temperature or summer aridity, or environmental stimuli may have permanent impacts on the animal, as in the case of temperature and sex determination, or carcinogen exposure and tumour development. Regulation of genes required to address these changes can be mediated through the epigenome.

Epigenetic regulation of gene expression is independent of changes to the genetic sequence and includes post-translational modifications of histones, incorporation of different histone isoforms into the nucleosome, and DNA methylation. Histone modifications and isoforms influence gene expression through recruitment or exchange of co-regulatory factors or by changing the strength of the interaction between the DNA strands and the histone octamer (Buschbeck et al. 2009; Herz et al. 2013; Kamakaka and Biggins 2005). DNA methylation occurs most commonly at cytosine residues in the context of cytosine-guanine dinucleotides ( $\mathrm{CpGs}$ ), and occurs by transfer of a methyl group from S-adenosylmethionine to cytosine to produce 5methylcytosine and S-adenosylhomocysteine by DNA methyltransferases (DNMTs). Methylated CpGs are recognized by methyl-CpG-binding proteins, which favour transcriptional silencing of the associated gene (Arand et al. 2012). DNA methylation was considered to be permanent for the life of the cell and to be inherited by its progeny, but experimental evidence of DNA methylation changes within the lifetime of a 
single cell (Metivier et al. 2008) instead support a more dynamic role, and suggest a stochastic model where the overall level of $\mathrm{CpG}$ methylation in a given region is maintained but individual CpG methylations are not (Jeltsch and Jurkowska 2014).

When studying epigenetic regulation of gene expression, it is important to consider whether the epigenetic mark under study represents a persistent memory for gene activation or silencing, or if it merely reflects the change in gene expression. For example, acetylation of lysine 9 or 27 of histone H3 (H3K9Ac, H3K27Ac) in nucleosomes at gene promoters is observed during active transcription of the associated gene (Wang et al. 2008) and treatment with histone lysine (de)acetylase inhibitors can alter gene transcription (Fernandez-Sanchez et al. 2013; Gui et al. 2004). However, few studies examine whether or not removal of the inhibitor returns transcription to pre-treated levels. Clarifying the cause-effect relationship between epigenetic marks and transcription is necessary to ultimately understand the epigenetic contribution to gene expression changes due to environmental stimuli.

In the present review, we discuss recent investigations into how environmental factors encountered by fish and herpetofauna impact their epigenomes through histone modification or isoform switching and/or DNA methylation (Figure 1), consider possible mechanistic implications of the experimental observations, and identify key areas for future research.

\subsection{Non-chemical environmental factors}

2.1.1. Temperature-dependent sex determination 
Fish and herpetofauna are poikilotherms; they do not maintain a constant internal temperature. Environmental temperature varies considerably between seasons in temperate regions and these long-term temperature variations require long-term, but non-permanent, changes in gene expression. Epigenetic regulation offers both a means to control expression of genes required only seasonally and those required during critical developmental periods.

Environmental temperature during a critical developmental time period is an important sex determination factor in many species of fish and reptiles (Azuma et al. 2004; Ferguson and Joanen 1982; Kitano et al. 1999; Koumoundouros et al. 2002). Recent studies have suggested that the mechanism of sex determination by temperature involves differential DNA methylation in the gonad in sexually dimorphic gene promoters of aromatase (cyp19a1), which encodes the enzyme that converts testosterone to $17 \beta$-estradiol, and sex determining region $\mathrm{Y}$ box 9 (sox9), which controls testis differentiation. In the European sea bass (Dicentrarchus labrax), rearing at a male-producing temperature during early life was found to increase DNA methylation in the cyp19a1 promoter, which correlated with decreased aromatase expression and increased masculinization in sexually undifferentiated individuals (Navarro-Martin et al. 2011). The authors identified two of seven CpG loci in the cyp19a1 promoter as temperature-sensitive with one particular locus conserved in related teleost species. This locus, at position -13 from the transcription start site, is near a Sry-related high mobility group (Sox) binding site and TATA box, while the other non-conserved locus at -431 is within $30 \mathrm{bp}$ of a forkhead box (Fox) binding site (Navarro-Martin et al. 2011). CpG methylation in the cyp19a1 promoter may represent a general mechanism for sex 
determination in response to temperature as increased $\mathrm{CpG}$ methylation has also been observed in alligator (Alligator mississippiensis) and red-eared slider turtle (Trachemys scripta elegans) embryos incubated at male-producing temperatures (Matsumoto et al. 2013; Parrott et al. 2014). Conversely, increased methylation of the sox9 promoter corresponded with decreased sox9 expression at female-producing temperatures (Parrott et al. 2014). Differential expression of dnmts was not observed suggesting that temperature may be affecting methyltransferase activity or localization directly; mechanisms that may be involved in communicating many environmental influences but that remain to be investigated.

Temperature fluctuations also affect installation of histone variants and deposition of post-translational modifications on histone tails in the common carp (Cyprinus carpio). The carp undergoes structural changes and alterations in ribosome biogenesis in its skeletal muscles to cope with seasonal temperature variations in its native temperate latitudes. In animals acclimated to winter temperatures, rRNA transcription decreases corresponding to the co-localization of $\mathrm{mH} 2 \mathrm{~A} 1$ and the H3K27me2 repressive mark at the promoter of the rRNA cistron (Araya et al. 2010). These were replaced by $\mathrm{mH} 2 \mathrm{~A} 2$ and the $\mathrm{H} 3 \mathrm{~K} 4 \mathrm{me} 3$ mark of active transcription in animals acclimated to summer conditions. This relationship was also observed for the acclimation-related ribosomal protein L41 (rp/41) gene, but not for prolactin ( $p r l)$. While these epigenetic marks and isoforms have been associated with transcriptional activation or silencing, they alone may not necessarily represent a specific method of temperature-sensitive regulation, and instead may simply be a consequence of increased transcription at these loci. The regulatory relationship between $\mathrm{mH} 2 \mathrm{~A}$ 
recruitment and increased rRNA transcription could be further elucidated through knockdown of the mH2A isoforms followed by measurement of rRNA and rp/41 expression during winter and summer conditions.

2.1.2. Environmental temperature mediates natural and thyroid hormone-induced metamorphosis

The North American bullfrog (Rana catesbeiana) overwinters in its larval tadpole form (Cecil and Just 1979) and has natural systems to modulate its development depending on the environmental temperature. The tissue-specific outcomes of metamorphosis from the aquatic tadpole to the semi-terrestrial adult is initiated by, and totally dependent on, thyroid hormone $(\mathrm{TH})$ and treatment with $\mathrm{TH}$ can induce the tadpole to undergo metamorphosis precociously. However, tadpoles acclimated to low, nonpermissive temperature $\left(4-5^{\circ} \mathrm{C}\right)$ will not undergo precocious metamorphosis when exposed to exogenous thyroid hormone as they would at higher, permissive temperature $\left(20-25^{\circ} \mathrm{C}\right)$, but elements of the $\mathrm{TH}$-induced gene expression program are nonetheless activated and may be responsible for forming a molecular memory of TH exposure (Ashley et al. 1968; Frieden et al. 1965; Hammond et al. 2015).

This phenomenon has been recently examined at the chromatin level. It was found that low temperature blocked the transfer of active chromatin marks, such as H3K9Ac and H3K36 methylation, to the transcribed regions of key metamorphic transcription factors including thyroid hormone receptor $\beta$ (thrb) and CCAAT/enhancer binding protein 1 (cebp1) in liver (Mochizuki et al. 2012a). This observation was consistent with the lack of induction of these genes by $\mathrm{TH}$ at low temperature, in 
contrast to the genic deposition of $\mathrm{H} 3 \mathrm{~K} 9 \mathrm{Ac}$ and $\mathrm{H} 3 \mathrm{~K} 36 \mathrm{me} 3$ marks that accompanied activation of the thrb gene in response to $\mathrm{TH}$ treatment at permissive temperature (Mochizuki et al. 2012b). While these epigenetic data support the hepatic transcriptional observations, genetic information was limited such that epigenetic marks at the gene promoters were not examined. The pending release of the bullfrog genome will enable the definition of the potential epigenetic molecular memory of TH treatment (http://www.genomebc.ca/news-events/news-releases/2013/genomics-leadinginnovation-bc/).

\subsubsection{Salinity and hatchery adaptation}

Diadromous fish must regulate gene expression pathways to adapt to changes in salinity as they exit their natal waterways and enter the ocean (and again when they return to spawn). Accordingly, changes in salinity can impact epigenomes of aquatic vertebrates. This may be of particular significance during migration between freshwater rivers and lakes and the ocean. Hatchery-raised fish tend to have low survival rates for their initial migration to the sea, which may be a result of adaptation to the hatchery environment. Work in other organisms suggested that declines in fitness due to different growth conditions was associated with genome-wide methylation changes (Kaeppler 1993; Peraza-Echeverria 2001), but these differences were not detected in freshwater hatchery-raised fish (Blouin et al., 2010). Indeed, a salt-enriched diet improved survival of freshwater hatchery-raised trout transferred to salt water, but the altered DNA methylation profile of the fish was not maintained (Moran et al. 2013). The transitory nature of the DNA methylation changes suggests that they were likely a consequence of 
other changes in gene expression, rather than the direct cause of them, and therefore that DNA methylation is not a major mechanism of adaptation to the hatchery environment.

\subsubsection{Aestivation and photoperiod}

DNA methyltransferases and DNA methylation by extension have been implicated in transcriptional silencing of skeletal muscle bioenergetic genes during aestivation; a period of low energy state and water conservation during drought or extreme temperature, in the green striped burrowing frog (Cyclorana alboguttata)(Hudson et al. 2008). Transcript levels of the DNA methyltransferase dnmt1 and the transcriptional co-repressor $\sin 3 a$ were significantly higher in aestivating adults than non-aestivators, but no direct evidence of differential DNA methylation or its regulatory consequence was provided. This is likely because, like many non-model wildlife species, there is limited genomic data available for $C$. alboguttata.

Similarly, a role for DNA methylation in the regulation of muscle growth rate by photoperiod was proposed in the Atlantic cod (Gadus morhua), where increased expression of $d n m t 1$ and $d n m t 3 a$ was detected in fast twitch muscle of G. morhua exposed to continuous illumination relative to fish reared under a natural photoperiod (Giannetto et al. 2013). Interestingly, this relationship was still maintained once the natural photoperiod was equal to that of the continuous illumination cohort, which suggests that increased dnmt expression is a lasting impact of the continuous illumination during rearing. Determination of the fitness and ability to respond to 
environmental challenges of fish raised under constant illumination would offer insight into the consequences of this increased dnmt expression.

\subsection{Chemical pollutants in the aquatic environment}

\subsubsection{Environmental estrogens}

Chemical contaminants possessing estrogenic activities are capable of altering DNA methylation in fish, but the contribution of these alterations to epigenetic memory is unclear. Ethinyl estradiol (EE2) is widely found in surface waters due to its common use in oral contraceptive pills and acts through the nuclear estrogen receptor to activate expression of sex-related genes including cyp19a1 and vitellogenin (vtg), an egg yolk precursor protein naturally expressed only by females (Belfroid et al. 1999; Kolpin et al. 2002). The three $\mathrm{CpG}$ sites of the vtg/ promoter are normally methylated in male zebrafish (Danio rerio) liver, and minimally methylated in female liver (Strömqvist et al. 2010). Treatment with $100 \mathrm{ng} / \mathrm{L}$ EE2 for 14 days reduced hepatic vtgl promoter methylation in both males and females, suggesting that induced expression of vtgl typically observed under these conditions may be mediated through reductions in $\mathrm{CpG}$ methylation. While the lifespan of zebrafish hepatocytes in vivo has not been determined, it is hundreds of days in mice (Magami et al. 2002); therefore the period of exposure was probably not sufficient for replication-dependent (passive) DNA demethylation to contribute significantly to the reduced promoter $\mathrm{CpG}$ methylation. Active demethylation may have contributed as well, perhaps through cytosine deamination followed by nucleotide or base excision and repair or cytosine demethylation in situ by the ten-eleven translocation (TET) proteins (Fritz and 
Papavasiliou 2010; Pastor et al. 2013; Ramchandani et al. 1999). Determination of the rapidity of the demethylation within the 14 day period would suggest an active mechanism, as would studying the expression of $d n m t$ genes and the putative enzymes involved in DNA demethylation.

Changes in $\mathrm{CpG}$ methylation at the promoters of other sex steroid metabolism and signalling genes have been identified as a consequence of exposure of males to EE2, but not females. Promoter hypermethylation of the steroid 17-alphamonooxygenase (cyp17a1) gene, which encodes an enzyme important in steroid biosynthesis, was observed in male testis but not female ovary following EE2 exposure of adult rare minnows (Gobiocypris rarus)(Liu et al. 2014). In adult Japanese medaka (Oryzias latipes), $\mathrm{CpG}$ sites identified in the estrogen receptor 1 (esr1) promoter that were not methylated in the male brain or testis became methylated upon EE2 treatment in a manner found in female tissues (Contractor et al. 2004). Similarly, EE2 exposure also increased cyp19a1 promoter $\mathrm{CpG}$ methylation in male liver and brain to a similar state found in females. Insight into the permanence of these methylation changes in males could be gained by measuring $\mathrm{CpG}$ methylation after EE2 removal, which was not performed in these studies. The transition to a female-like DNA methylation profile in these genes was not accompanied by the expected effects on O. latipes ESR1 or aromatase expression. More recent work in related species has identified additional potential sites of DNA methylation in the cyp19a1 promoter, so the disconnect between the DNA methylation changes and gene expression in $O$. latipes may be due to incomplete characterization of the promoter CpG sites (Wen et al. 2014). Alternatively, 
the feminizing effects of EE2 may be primarily mediated through other epigenetic modifications or other non-epigenetic methods.

DNA methylation can also be affected by the estrogenic herbicide breakdown product 2,4-dichlorophenol (2,4-DCP) (Ma et al. 2012). Increased global DNA methylation and increased $d n m t 1$ and $d n m t 3$ transcript levels were detected 5 days after exposure of adult goldfish (Carassius auratus) to as little as $0.01 \mathrm{mg} / \mathrm{L} \mathrm{2,4-DCP}$ (Zhang et al. 2014). Co-treatment with 2,4-DCP and the DNMT inhibitor 5-AC or the Sadenosylmethionine depletion agent, sodium selenite, prevented this hypermethylation, but the impact of these observations on the disruption of estrogen-regulated gene expression by 2,4-DCP was not investigated.

\subsubsection{Polychlorinated biphenyls (PCBs)}

Killifish from sites with high levels of PCB contamination are more resistant to PCBs than those from less-contaminated sites (Elskus et al. 1999; Nacci et al. 1999) . Killifish from New Bedford Harbor, ME, have an overall reduced level of signalling mediated by aryl hydrocarbon receptor (Ahr), which includes resistance to induction of aryl hydrocarbon hydroxylase (Cyp1a1), a cytochrome P450 enzyme (Bello et al. 2001). Aluru et al. (2011) hypothesized that this lack of Cyp1a1 induction would be associated with promoter $\mathrm{CpG}$ hypermethylation of the two killifish Ahr isoforms. However, bisulfite sequencing of the two promoters revealed that there was no significant difference in CpG methylation between the New Bedford Harbor fish and fish from a reference site (Aluru et al. 2011). Killifish from another site of high PCB contamination, Elizabeth River, VA, did not have detectable methylation in any of a limited set of CpG sites in the 
cyp1a1 promoter, despite a similar refractory phenotype (Timme-Laragy et al. 2005). The hypothesis that $\mathrm{CpG}$ methylation is responsible for this phenotype was also not supported by a study where PCB-resistant killifish from Newark Bay, NJ, were treated with 5-AC (Arzuaga et al. 2004). PCB-resistant fish co-treated with the Cyp1a inductive agent 3,3',4,4',5-pentachlorobiphenyl (IUPAC PCB126) and 5-AC showed no increase in Cyp1a catalytic activity, while the expected increase in activity was detected in fish treated with PCB126 alone. Although the PCB-resistant phenotype observed in these wild killifish does not seem to be due to $\mathrm{CpG}$ methylation and silencing of cyp1a1, an epigenetic repression mechanism is almost certainly at play as laboratory-raised $F_{1}$ generation fish from the Elizabeth River population regain Cyp1a inducibility during development (Meyer et al. 2002).

\subsubsection{Heavy Metals and Arsenic}

The level of global DNA methylation is considered a rough measure of the level of transcriptional activity in an organism under particular conditions. DNA hypomethylation has been associated with development of cancer, but whether it is a cause of the disease or a symptom of general dysregulation of gene expression is unclear (Ehrlich 2009; Esteller and Herman 2002). For organisms with few molecular tools available, it is a common first parameter to examine for gross effects of environmental heavy metal exposure. Several recent studies of the impact of heavy metal exposure on global genome methylation in fish have yielded differing results, demonstrating the variety of mechanisms of disruption possible among this broad class of contaminants and the importance of carefully selecting the exposure conditions. 
Surface waters may be contaminated with heavy metals from natural and anthropogenic sources. Cadmium and methylmercury $(\mathrm{meHg})$ primarily enter surface waters from industrial or mining operations, while the anti-fouling agents tributyltin (TBT) and triphenyltin (TPT) leach from painted ship hulls (Andres et al. 2000; Boening 2000; Thomas et al. 2001; Tolosa et al. 1996). Cadmium exposure increased hepatic genome methylation in European eels (Anguilla anguilla) (Pierron et al. 2014). The authors used an immunosorbent assay and an arbitrarily primed PCR method to measure the level of methylation, due to the paucity of tools available for this endangered species. Of particular concern, however, was the decrease in overall RNA synthesis caused by the environmentally-relevant concentrations of cadmium. Hepatic DNA hypomethylation was observed in false kelpfish (Sebastiscus marmoratus) exposed to TBT or TPT, but the authors did not monitor the animals for tumour formation (Wang et al. 2009). The authors found that rather than directly affecting DNA methylating or demethylating enzymes, TBT and TPT caused DNA hypomethylation by disrupting the balance of methyl donors such that S-adenosylhomocysteine was in excess of $S$ adenosylmethionine. Yellow perch (Perca flavescens) exposed to MeHg showed no significant difference in global DNA methylation, as determined by the LUMA assay (Basu et al. 2013). A lack of transgenerational MeHg effects on global genome methylation in zebrafish has also been noted (Olsvik et al. 2014).

Arsenic enters surface waters through industrial processes and natural weathering of arsenic-containing ores (Smedley and Kinniburgh 2002). Zebrafish embryos treated with $2 \mathrm{mM}$ arsenite $\left(\right.$ as $\left.\mathrm{NaAsO}_{2}\right)$ were shown to have disrupted patterns of DNA methylation using an immunostaining technique (Li et al. 2009). 
Methylation in the trunk and tail regions of embryos exposed to arsenite post-fertilization was reduced by 24 hours post-fertilization (hpf). By $48 \mathrm{hpf}$, methylation in these regions had diminished in the controls but was increased throughout the arsenite-treated embryos. However, only $66 \%$ of embryos hatched at this exposure level, which is above the reported $96 \mathrm{~h} \mathrm{LC} 50$ of $772 \mu \mathrm{M}$ (Salisbury 2006). The disruptions to DNA methylation, as well as the morphological abnormalities and overt physiological disruption observed in the embryos must therefore be considered in the context of the high embryonic lethality caused by the arsenic exposure.

\section{Closing remarks}

It is clear that epigenetics contribute to organismal responses to their environment, whether natural or man-made. While fish and herpetofauna present particularly interesting examples of genome/environment interactions, our understanding regarding the contribution of specific epigenetic mechanisms is underdeveloped. So far, the majority of studies involving epigenetic changes in fish and herpetofauna have focussed on profiling a specific epigenetic mark(s) or used broad methylation state readouts rather than investigating the mechanistic relationship between the epigenetic landscape and changes in gene expression in response to an environmental stimulus. This is mostly due to a paucity of genetic sequence information to perform genome-wide experiments. As this issue is overcome, we will arrive at a greater understanding of the ways that these important organisms respond to changes in their environments, which is critical due to the acceleration of human industrial activity and global climate change. These studies nonetheless provide important insights and 
testable hypotheses for epigenetic changes in fish and herpetofauna as they contend with environmental insults, as well as potential mechanisms by which important events in their lifecycles may be impacted by their changing environments. 
Figure Legend

Figure 1. Environmental factors that have known influence on herpetofauna or fish epigenomes through histone modification or isoform switching and/or DNA modification through methylation. 


\section{References}

Aluru, N., Karchner, S.I., and Hahn, M.E. 2011. Role of DNA methylation of AHR1 and AHR2 promoters in differential sensitivity to PCBs in Atlantic Killifish, Fundulus heteroclitus. Aquat Toxicol 101, 288-294.

Andres, S., Ribeyre, F., Tourencq, J.N., and Boudou, A. 2000. Interspecific comparison of cadmium and zinc contamination in the organs of four fish species along a polymetallic pollution gradient (Lot River, France). Sci Total Environ 248, 11-25.

Arand, J., Spieler, D., Karius, T., Branco, M.R., Meilinger, D., Meissner, A., Jenuwein, T., Xu, G., Leonhardt, H., Wolf, V., and Walter, J. 2012. In vivo control of CpG and non-CpG DNA methylation by DNA methyltransferases. PLoS Genetics 8, e1002750.

Araya, I., Nardocci, G., Morales, J.P., Vera, M.I., Molina, A., and Alvarez, M. 2010. MacroH2A subtypes contribute antagonistically to the transcriptional regulation of the ribosomal cistron during seasonal acclimatization of the carp fish. Epigenet Chromatin 3, 14.

Arzuaga, X., Calcaño, W., and Elskus, A. 2004. The DNA de-methylating agent 5azacytidine does not restore CYP1A induction in PCB resistant Newark Bay killifish (Fundulus heteroclitus). Mar Environ Res 58, 517-520.

Ashley, H., Katti, P., and Frieden, E. 1968. Urea excretion in bullfrog tadpole - Effect of temperature, metamorphosis, and thyroid hormones. Dev Biol 17, 293-307.

Azuma, T., Takeda, K., Doi, T., Muto, K., Akutsu, M., Sawada, M., and Adachi, S. 2004. The influence of temperature on sex determination in sockeye salmon Oncorhynchus nerka. Aquaculture 234, 461-473. 
Basu, N., Head, J., Nam, D.H., Pilsner, J.R., Carvan, M.J., Chan, H.M., Goetz, F.W., Murphy, C.A., Rouvinen-Watt, K., and Scheuhammer, A.M. 2013. Effects of methylmercury on epigenetic markers in three model species: mink, chicken and yellow perch. Comp Biochem Physiol C 157, 322-327.

Belfroid, A.C., Van der Horst, A., Vethaak, A.D., Schäfer, A.J., Rijs, G.B., Wegener, J., and Cofino, W.P. 1999. Analysis and occurrence of estrogenic hormones and their glucuronides in surface water and waste water in The Netherlands. Sci Total Environ 225, 101-108.

Bello, S.M., Franks, D.G., Stegeman, J.J., and Hahn, M.E. 2001. Acquired resistance to Ah receptor agonists in a population of Atlantic killifish (Fundulus heteroclitus) inhabiting a marine superfund site: in vivo and in vitro studies on the inducibility of xenobiotic metabolizing enzymes. Toxicol Sci 60, 77-91.

Blouin, M.S., Thuillier, V., Cooper, B., Amarasinghe, V., Cluzel, L., Araki, H., and Grunau, C. 2010. No evidence for large differences in genomic methylation between wild and hatchery steelhead (Oncorhynchus mykiss). Can J Fish Aquat Sci 67, 217-224.

Boening, D.W. 2000. Ecological effects, transport, and fate of mercury: a general review. Chemosphere 40, 1335-1351.

Buschbeck, M., Uribesalgo, I., Wibowo, I., Rué, P., Martin, D., Gutierrez, A., Morey, L., Guigó, R., López-Schier, H., and Di Croce, L. 2009. The histone variant macroH2A is an epigenetic regulator of key developmental genes. Nature Struct Mol Biol 16, 1074-1079. 
Cecil, S.G. and Just, J.J. 1979. Survival rate, population density and development of a naturally occurring anuran larvae (Rana catesbeiana). Copeia 3, 447-453.

Contractor, R.G., Foran, C.M., Li, S., and Willett, K.L. 2004. Evidence of gender-and tissue-specific promoter methylation and the potential for ethinylestradiol-induced changes in Japanese medaka (Oryzias latipes) estrogen receptor and aromatase genes. J. Toxicol. Environ. Health 67, 1-22.

Ehrlich, M. 2009. DNA hypomethylation in cancer cells. Epigenomics 1, 239-259.

Elskus, A.A., Monosson, E., McElroy, A.E., and Stegeman, J.J., Woltering, D.S. 1999. Altered CYP1A expression in Fundulus heteroclitus adults and larvae: a sign of pollutant resistance? Aquat Toxicol 45, 99-113.

Esteller, M. and Herman, J.G. 2002. Cancer as an epigenetic disease: DNA methylation and chromatin alterations in human tumours. J Pathol 196, 1-7.

Ferguson, M.W.J. and Joanen, T. 1982. Temperature of egg incubation determines sex in Alligator mississippiensis. Nature 296, 850-853.

Fernández-Sánchez, A., Baragaño Raneros, A., Carvajal Palao, R., Sanz, A.B., Ortiz, A., Ortega, F., Suárez-Álvarez, B., and López-Larrea, C. 2013. DNA demethylation and histone $\mathrm{H} 3 \mathrm{~K} 9$ acetylation determine the active transcription of the NKG2D gene in human CD8+ T and NK cells. Epigenetics 8, 66-78.

Frieden, E., Wahlborg, A., and Howard, E. 1965. Temperature control of response of tadpoles to triiodothyronine. Nature 205, 1173-1176.

Fritz, E.L. and Papavasiliou, F.N. 2010. Cytidine deaminases: AIDing DNA demethylation? Genes Dev 24, 2107-2114. 
Giannetto, A., Nagasawa, K., Fasulo, S., and Fernandes, J.M. 2013. Influence of photoperiod on expression of DNA (cytosine-5) methyltransferases in Atlantic cod. Gene 519, 222-230.

Gui, C.Y., Ngo, L., Xu, W.S., Richon, V.M., and Marks, P.A. 2004. Histone deacetylase (HDAC) inhibitor activation of p21 ${ }^{\text {WAF1 }}$ involves changes in promoter-associated proteins, including HDAC1. Proc Natl Acad Sci USA 101, 1241-1246.

Hammond, S., Veldhoen, N., and Helbing, C. 2015. Influence of temperature on thyroid hormone signaling and endocrine disruptor action in Rana (Lithobates) catesbeiana tadpoles. Gen Comp Endocrinol 219, 6-15.

Herz, H.M., Garruss, A., and Shilatifard, A. 2013. SET for life: biochemical activities and biological functions of SET domain-containing proteins. Trends in Biochem Sci 38, 621-639.

Hudson, N.J., Lonhienne, T.G., Franklin, C.E., Harper, G.S., and Lehnert, S.A. 2008. Epigenetic silencers are enriched in dormant desert frog muscle. J Comp Physiol B 178, 729-734.

Jeltsch, A. and Jurkowska, R.Z. 2014. New concepts in DNA methylation. Trends in Biochem Sci 39, 310-318.

Kamakaka, R.T. and Biggins, S. 2005. Histone variants: deviants? Genes Dev 19, 295310.

Kitano, T., Takamune, K., Kobayashi, T., Nagahama, Y., and Abe, S.I. 1999. Suppression of P450 aromatase gene expression in sex-reversed males produced by rearing genetically female larvae at a high water temperature during a period of 
sex differentiation in the Japanese flounder (Paralichthys olivaceus). J Mol Endocrinol 23, 167-176.

Kolpin, D.W., Furlong, E.T., Meyer, M.T., Thurman, E.M., Zaugg, S.D., Barber, L.B., and Buxton, H.T. 2002. Pharmaceuticals, hormones, and other organic wastewater contaminants in U.S. streams, 1999-2000: A national reconnaissance. Environ Sci Technol 36, 1202-1211.

Koumoundouros, G., Pavlidis, M., Anezaki, L., Kokkari, C., Sterioti, K., Divanach, P., and Kentouri, M. 2002. Temperature sex determination in the European sea bass, Dicentrarchus labrax (L., 1758) (Teleostei, Perciformes, Moronidae): Critical sensitive ontogenetic phase. J Exp Zool 292, 573-579.

Li, D., Lu, C., Wang, J., Hu, W., Cao, Z., Sun, D., Xia, H., and Ma, X. 2009.

Developmental mechanisms of arsenite toxicity in zebrafish (Danio rerio) embryos. Aquat Toxicol 91, 229-237.

Liu, Y., Chen, S., Liu, S., Zhang, Y., Yuan, C., and Wang, Z. 2014. DNA methylation in the 5' flanking region of cytochrome P450 17 in adult rare minnow Gobiocypris rarus - tissue difference and effects of $17 \alpha$-ethinylestradiol and $17 \alpha$ methyltestoterone exposures. Comp Biochem Physiol 162, 16-22.

Ma, Y., Han, J., Guo, Y., Lam, P.K., Wu, R.S., Giesy, J.P., Zhang, X., and Zhou, B. 2012. Disruption of endocrine function in in vitro H295R cell-based and in in vivo assay in zebrafish by 2,4-dichlorophenol. Aquat Toxicol 106-107, 173-181.

Magami, Y., Azuma, T., Inokuchi, H., Kokuno, S., Moriyasu, F., Kawai, K., and Hattori, T. 2002. Cell proliferation and renewal of normal hepatocytes and bile duct cells in adult mouse liver. Liver 22, 419-425. 
Matsumoto, Y., Buemio, A., Chu, R., Vafaee, M., and Crews, D. 2013. Epigenetic control of gonadal aromatase (cyp19a1) in temperature-dependent sex determination of red-eared slider turtles. PloS One 8, e63599.

Métivier, R., Gallais, R., Tiffoche, C., Le Péron, C., Jurkowska, R.Z., Carmouche, R.P., Ibberson, D., Barath, P., Demay, F., Reid, G., Benes, V., Jeltsch, A., Gannon, F., and Salbert, G. 2008. Cyclical DNA methylation of a transcriptionally active promoter. Nature 452, 45-50.

Meyer, J.N., Nacci, D.E., and Di Giulio, R.T. 2002. Cytochrome P4501A (CYP1A) in Killifish (Fundulus heteroclitus): Heritability of Altered Expression and Relationship to Survival in Contaminated Sediments. Toxicol Sci $68,69-81$.

Mochizuki, K., Goda, T., and Yamauchi, K. 2012a. Gene expression profile in the liver of Rana catesbeiana tadpoles exposed to low temperature in the presence of thyroid hormone. Biochem Biophys Res Commun 420, 845-850.

Mochizuki, K., Ishihara, A., Goda, T., and Yamauchi, K. 2012b. RNA polymerase II phosphorylation at serine 2 and histone $\mathrm{H} 3$ tri-methylation at lysine 36 are key steps for thyroid hormone receptor beta gene activation by thyroid hormone in Rana catesbeiana tadpole liver. Biochem Biophys Res Commun 417, 1069-1073. Morán, P., Marco-Rius, F., Megías, M., Covelo-Soto, L., and Pérez-Figueroa, A. 2013. Environmental induced methylation changes associated with seawater adaptation in brown trout. Aquaculture 392, 77-83.

Nacci, D., Coiro, L., Champlin, D., Jayaraman, S., McKinney, R., Gleason, T.R., Munns Jr, W.R., Specker, J.L., and Cooper, K.R. 1999. Adaptations of wild populations of 
the estuarine fish Fundulus heteroclitus to persistent environmental contaminants. Mar Biol 134, 9-17.

Navarro-Martín, L., Viñas, J., Ribas, L., Díaz, N., Gutiérrez, A., Di Croce, L., and Piferrer, F. 2011. DNA methylation of the gonadal aromatase (cyp19a) promoter is involved in temperature-dependent sex ratio shifts in the European sea bass. PLoS Genet 7, e1002447.

Olsvik, P.A., Williams, T.D., Tung, H.S., Mirbahai, L., Sanden, M., Skjaerven, K.H., and Ellingsen, S. 2014. Impacts of TCDD and MeHg on DNA methylation in zebrafish (Danio rerio) across two generations. Comp Biochem Physiol C 165, 17-27.

Parrott, B.B., Kohno, S., Cloy-McCoy, J.A., and Guillette, L.J., Jr. 2014. Differential incubation temperatures result in dimorphic DNA methylation patterning of the SOX9 and aromatase promoters in gonads of alligator (Alligator mississippiensis) embryos. Biol Reprod 90, 1-11.

Pastor, W.A., Aravind, L., and Rao, A. 2013. TETonic shift: biological roles of TET proteins in DNA demethylation and transcription. Nat Rev Mol Cell Biol 14, 341356.

Pierron, F., Baillon, L., Sow, M., Gotreau, S., and Gonzalez, P. 2014. Effect of low-dose cadmium exposure on DNA methylation in the endangered European eel. Environ Science Technol 48, 797-803.

Ramchandani, S., Bhattacharya, S.K., Cervoni, N., and Szyf, M. 1999. DNA methylation is a reversible biological signal. Proc Natl Acad Sci USA 96, 6107-6112. 
Salisbury, H. 2006. Evaluation of a transgenic zebrafish model for assessing arsenic toxicity. Thesis. Toxicology, University of Saskatchewan, Saskatoon, Saskatchewan.

Smedley, P.L. and Kinniburgh, D.G. 2002. A review of the source, behaviour and distribution of arsenic in natural waters. Appl Geochem 17, 517-568.

Strömqvist, M., Tooke, N., and Brunström, B. 2010. DNA methylation levels in the $5^{\prime}$ flanking region of the vitellogenin I gene in liver and brain of adult zebrafish (Danio rerio)-sex and tissue differences and effects of $17 \alpha$-ethinylestradiol exposure. Aquat Toxicol 98, 275-281.

Thomas, K.V., Fileman, T.W., Readman, J.W., and Waldock, M.J. 2001. Antifouling Paint Booster Biocides in the UK Coastal Environment and Potential Risks of Biological Effects. Mar Pollut Bull 42, 677-688.

Timme-Laragy, A.R., Meyer, J.N., Waterland, R.A., and Di Giulio, R.T. 2005. Analysis of CpG methylation in the killifish CYP1A promoter. Comp Biochem Physiol C 141, 406-411.

Tolosa, I., Readman, J.W., Blaevoet, A., Ghilini, S., Bartocci, J., and Horvat, M. 1996. Contamination of Mediterranean (Côte d'Azur) coastal waters by organotins and Irgarol 1051 used in antifouling paints. Mar Pollut Bull 32, 335-341.

Wang, Y., Wang, C., Zhang, J., Chen, Y., and Zuo, Z. 2009. DNA hypomethylation induced by tributyltin, triphenyltin, and a mixture of these in Sebastiscus marmoratus liver. Aquat Toxicol 95, 93-98.

Wang, Z., Zang, C., Rosenfeld, J.A., Schones, D.E., Barski, A., Cuddapah, S., Cui, K., Roh, T.Y., Peng, W., Zhang, M.Q., and Zhao, K. 2008. Combinatorial patterns of 
histone acetylations and methylations in the human genome. Nat Genet $40,897-$ 903.

Wen, A.Y., You, F., Sun, P., Li, J., Xu, D.D., Wu, Z.H., Ma, D.Y., and Zhang, P.J. 2014. CpG methylation of dmrt1 and cyp19a promoters in relation to their sexual dimorphic expression in the Japanese flounder Paralichthys olivaceus. J Fish Biol 84, 193-205.

Zhang, X., Li, H., Qiu, Q., Qi, Y., Huang, D., and Zhang, Y. 2014. 2,4-Dichlorophenol induces global DNA hypermethylation through the increase of $S$ adenosylmethionine and the upregulation of DNMTs mRNA in the liver of goldfish Carassius auratus. Comp Biochem Physiol C 160, 54-59. 


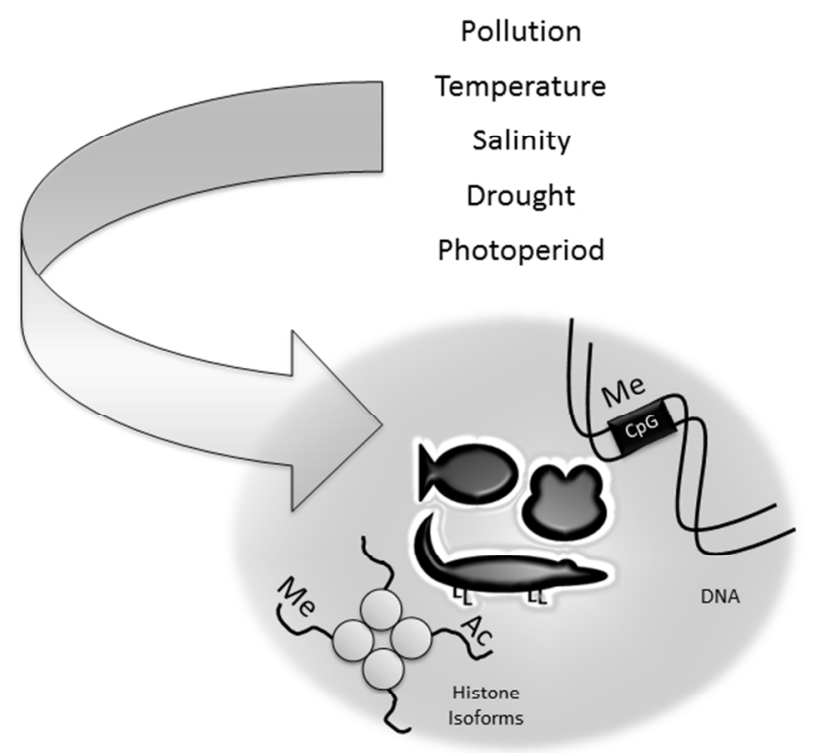

Figure 1. Environmental factors that have known influence on herpetofauna or fish epigenomes through histone modification or isoform switching and/or DNA modification through methylation. $254 \times 190 \mathrm{~mm}$ (96 x 96 DPI) 